\title{
Use of Steel Industry By-products in Sustainable Civil Engineering Applications
}

\author{
Beste Çubukçuoğlu* \\ Department of Civil Engineering, Faculty of Civil and Environmental Engineering, Near East University, Nicosia, Northern Cyprus
}

\begin{abstract}
The concept of sustainability has been growing for many years. In parallel to this popularity, the use of sustainable materials in the construction industry has increased significantly. Sustainable construction materials should be proposed and introduced to the construction industry, mostly as a replacement for cement. Cement is one of the most commonly used construction materials, which produces very high carbon emissions. As the most widely used building material in the world, concrete is predominantly comprised of cement. Therefore, sustainable alternative constituents to cement are required. This study focuses on alternative materials to cement and additionally, alternative materials to naturally available aggregates. The physical, chemical characteristics and mineralogical properties of the proposed materials are investigated and the results are demonstrated in this research study. The findings highlight the environmental and economic potential of replacing cement and other binding materials with steel slag.
\end{abstract}

\section{Introduction}

Most buildings are structurally made from steel. However, concrete buildings offer many advantages over steel skeleton structures in terms of safety. Concrete structures are more resistant to very high temperatures for longer periods of time and hence offer excellent protection from explosions. Burj Khalifa in Dubai is a good example of a concrete-based buildings, where around 330,000 cubic meters of concrete was used to complete its construction. Concrete accelerates the construction process due to its ability to be prefabricated off site, unlike steel. When time means money, it becomes a very attractive option when selecting the right material to be used in the construction process. On the other hand, steel could be a cheaper and more environmentally friendly option compared to concrete due to the high carbon emissions generated by concrete during its production process.

Steel is a recyclable material and currently to protect the environment, reinforcing steel is the most commonly used material. Rebar is mostly made of $100 \%$ recycled scrap steel and at the end of its life cycle, it can be recovered, recycled and used again. In reality, as both concrete and steel have advantages and disadvantages, this leads to the question of why one should be chosen over the other when it is possible to apply them together. Reinforcing concrete with steel has major benefits. It is significantly better than using either concrete or steel on their own. Steel manufacturing creates a large amount of waste and by-products, which are discarded into the environment. Therefore, every step should be taken in order to recycle or possibly reuse them in the production of other products. Steel slag is a by-product generated during the electric arc furnace (EAF) process in steel production, in which approximately $100-150 \mathrm{~kg}$ of slag is produced per tonne of steel [1]. EAF uses zinc-coated steel scrap as the raw material. When the molten steel is separated from its impurities in the steel-making furnaces, the EAF steel slag (hereafter defined as steel slag) is produced. Steel slag contains high proportions of $\mathrm{MgO}$ and $\mathrm{CaO}$, where both can react with water. This introduces cementitious and/or pozzolanic properties to steel slag, which makes it possible for it to be used as a cement replacement material. Steel slag contains trace amounts of $\mathrm{Pb}$ and $\mathrm{Zn}$ since it is a by-product of the steel manufacturing industry. However, according to the Environment Agency Technical Guidance WM2, this material cannot be classified as hazardous when the amounts of both $\mathrm{Pb}$ and $\mathrm{Zn}$ are less than the $0.25 \%$ limit. Nevertheless, due to the vast amount of steel slag generation, its utilisation has become mandatory. This helps to reduce the amount of steel slag that must be disposed of and to evaluate the valuable ingredients of steel slag in different fields of application. Steel slag along with Basic oxygen Furnace (BOF) slag have been widely used in the fields of road construction, waterway construction, and small amounts are used as aggregates for concrete. Steel slags have different chemical constituents compared to BOF slags. The main chemical constituents of steel slag are differentiated depending on the properties of the recycled steel [2]. In the last few years, steel slag has been used as a cement component in the cement clinker manufacturing process. The partial substitution of clinker in cement production reduces the specific $\mathrm{CO}_{2}$ emissions. The demand for slag-cement enhances the durability of concrete and high density. It has been determined that steel slag-cement can save

\footnotetext{
* Corresponding author: beste.cubukcuoglu@neu.edu.tr
} 
energy, preserve virgin natural resources and exhibits highly satisfactory strength development with further long-term strength development.

In this study, steel slag was selected for use as cement replacement material and hence as a sustainable alternative binding agent to cement in concrete production. It was chosen due to its well-known physical and chemical characteristics and its wide range of application as a supplementary cementitious material and basis for energy-saving cement. Hence, it was expected to achieve good strength development and high durability with a very low hydration heat.

The water/binder matrix has a significant effect on the performance of the final product. This work aims to provide sufficient information to validate the potential viability of using steel slag as a binding agent in concrete production. This research work addresses these issues by performing a rigorous and systematic experimental programme that addresses the use of steel slag as a partial replacement for Ordinary Portland cement (PC). Hence, the performance of steel slag blended S products was tested through both physical and chemical tests and the corresponding results are depicted in this paper. However, this paper only focuses on the physical properties of the cement pastes rather than concrete that includes natural aggregates; hence, the leaching and chemical characteristics and microstructure of stabilised/solidified products including PC and its blends with steel slag are also demonstrated and discussed in this study. The results of replacing Portland cement type I (CEMI) with steel slag at ratios of CEMI-slag-1:2 and 1:4 are demonstrated.

Due to the current increase in environmental awareness and the resulting need for sustainable development, it is important to introduce more environmentally friendly and sustainable construction materials into the construction industry. Sustainable construction materials should not only be environmental friendly, but should also provide high levels of safety and cost effectiveness in the long term. The concept of sustainability has been growing for many years. In parallel to this popularity, the use of sustainable construction materials in the construction industry has increased significantly. Sustainable construction materials should be proposed and introduced into the construction industry, mostly as a replacement for cement. Cement is one of the most commonly used construction materials with very high carbon emissions. As the most widely used building material in the world, concrete is mainly comprised of cement. Therefore, sustainable alternative constituents to cement are required. This study focuses on the alternative materials to cement. Low grade magnesium oxide, pulverised fuel ash, steel slag and hydrated lime are the materials proposed as cement replacements. The physical and chemical characteristics of the proposed materials are investigated and the results are demonstrated in this research study. Morever, mineralogical analyses are also represented in this study.

\section{Materials and Methodology}

The replacement materials should have the same levels of cost-effectiveness as cement. The cost of the binders may cause severe restrictions regarding the type and quantity of binder that can be used. Hence, materials that is cheaper than and as effective as cement should be selected. In this study, steel slag is selected as a cement replacement. The selection of binders was based on the effectiveness and cost of the materials compared to cement. CEM1 (ASTM C150-89) was used in this study. Steel slag was provided by Tata Steel Europe. An ELGA-Purelab Option-R was used for the deionization of tap water. The main reason for using deionised water was to prevent any possible reaction of the ions with the chemicals in the binders (CEMI and slag). The chemical composition of the materials used in the study is given in Table 1.

Setting time, UCS before and after WI, workability, bulk density (BD) and moisture content (MC) measurements were conducted to analyse both the physical and chemical characteristics of the samples studied.

Table 1. Chemical Composition of CEMI and Slag.

\begin{tabular}{|c|c|c|}
\hline Compound & Steel Slag (\%) & CEMI \\
\hline $\mathrm{CaO}$ & 17.24 & 63.78 \\
\hline $\mathrm{SiO}_{2}$ & 14.66 & 20.33 \\
\hline $\mathrm{Al}_{2} \mathrm{O}_{3}$ & 9.70 & 4.47 \\
\hline $\mathrm{MgO}$ & 21.61 & 1.07 \\
\hline $\mathrm{Fe}_{2} \mathrm{O}_{3}$ & 24.89 & 2.52 \\
\hline $\mathrm{MnO}_{\mathrm{P}_{2} \mathrm{O}_{5}}$ & 2.69 & - \\
\hline $\mathrm{TiO}_{2}$ & 0.12 & - \\
\hline $\mathrm{S}$ & 0.23 & - \\
\hline $\mathrm{K}_{2} \mathrm{O}$ & 0.27 & 3.09 \\
\hline $\mathrm{ZnO}$ & 0.17 & 0.81 \\
\hline & 0 & - \\
\hline
\end{tabular}

The mineral composition of steel slag varies due to its varied chemical composition. According to the literature, the most common minerals found in steel slags are olivine $\left((\mathrm{Mg}, \mathrm{Fe})_{2} \mathrm{SiO}_{4}\right)$, merwinite $\left(\mathrm{Ca}_{3} \mathrm{Mg}\left(\mathrm{SiO}_{4}\right)_{2}\right)$, $\mathrm{C}_{3} \mathrm{~S}, \mathrm{C}_{2} \mathrm{~S}, \mathrm{C}_{4} \mathrm{AF}, \mathrm{C}_{2} \mathrm{~F}$, free $\mathrm{CaO}$ and $\mathrm{RO}$ phase (FeO$\mathrm{MnO}-\mathrm{CaO}-\mathrm{MgO}$ ) [3], [4]. Steel slag owes its cementitious properties to its $\mathrm{C}_{3} \mathrm{~S}, \mathrm{C}_{2} \mathrm{~S}, \mathrm{C}_{4} \mathrm{AF}$ and $\mathrm{C}_{2} \mathrm{~F}$ content. A high $\mathrm{MgO}$ content in steel slag is mostly due to the dolomite $\left(\mathrm{CaMg}\left(\mathrm{CO}_{3}\right)_{2}\right)$ used as a flux and to the $\mathrm{MgO}$ refractory used as the lining of the steel furnace [5]. Steel slag is mostly used as a raw material in cement production and is commercialised as steel slag cement. In China, $40 \%$ of the steel slag produced is used for this purpose. The product has good quality and is mainly used for general construction purposes and pavement applications [4]. Due to the fact that it is a by-product of steel as well as its ease of application, steel slag has been chosen as a potential cement replacement and binder. 


\section{Results and Discussion}

\subsection{Physical Characteristics of Solidified Products}

The specific surface area of steel slag used in this study was not calculated, but according to [6], it is possible to say that the specific surface of the slag is reduced as the particle size increases. Thus, no additional water is required with further incorporation of steel slag into the mortar.

\subsubsection{Setting Time}

It is known from the literature that when PC is partially replaced with steel slag, this results in weaker strength development and longer setting times [7]. In the present study, it was observed that the incorporation of steel slag into the mix matrix retarded the hydration and hence the setting of the grout.

The chemical characterisation and elemental composition of materials used in the study provide information on the factors that impact the setting time.

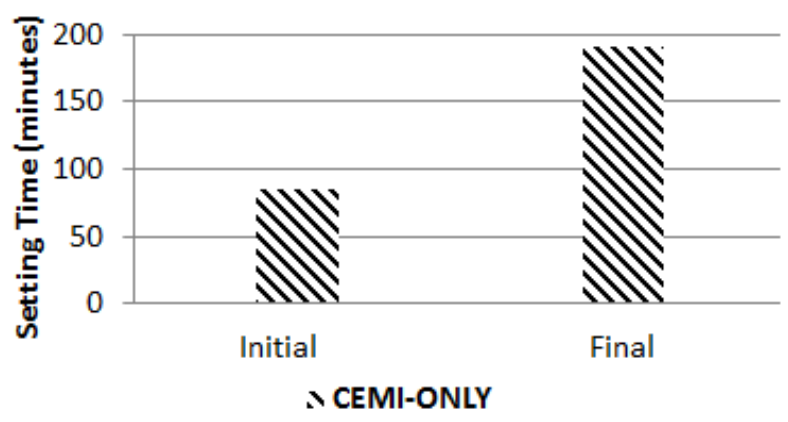

Fig. 1. CEMI-only - The effect of cement on setting time.

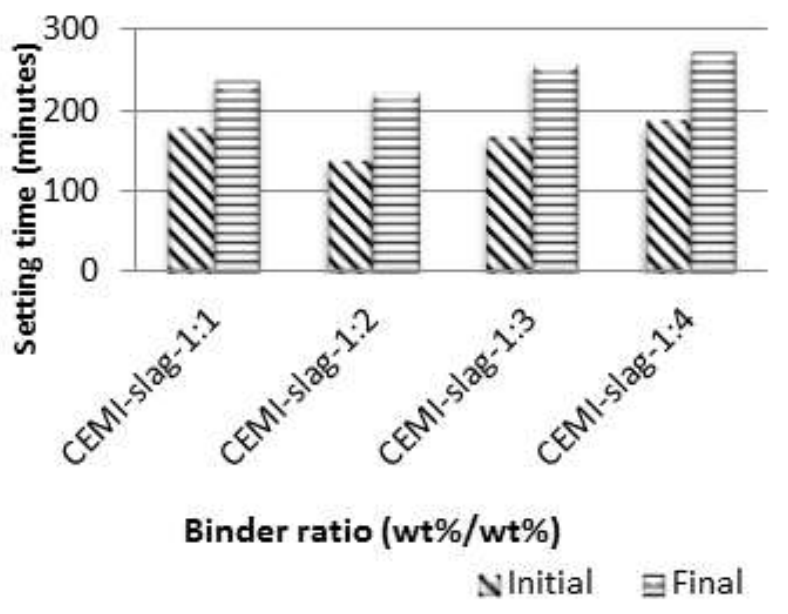

Fig. 2. CEMI-slag 1:1-1:4 - The effect of slag addition on the setting time.

\subsubsection{UCS before and after Water Immersion}

Samples at various CEMI/binder ratios were prepared in triplicate, cured for 7, 28 (before and after WI) and 56 days, and then tested. In addition to 28 days testing of strength, some samples were cured for either shorter or longer periods of time in order to verify the effect of the curing period on strength development. Certain selected samples were cured for $70,120,180,365,450$ and 630 days and the results achieved are provided.

The slag-blended mixtures were tested according to their effect on strength development and the results are depicted in Figure 1. According to the results obtained, it is clear that slag achieves much better strength development than hlime, $\mathrm{LGMgO}$ and even PFA, with UCS values increasing up to $50 \mathrm{MPa}$. Moreover, all ratios tested yielded higher than $5 \mathrm{MPa}$, regardless of the curing age, which is well above the UCS WAC limit $(1 \mathrm{MPa})$. The blends showed promising strength development even at 7 days of curing and it continued even after 56 days. There were only slight differences in the results obtained before and after WI.

The increase in the steel slag content of the matrix reduces the cement content in the mix and hence the cement dilution effect required for the hydration process. The hydration process slows down and longer setting times and delayed strength are expected. Altun and [8] stated that the high $\mathrm{MgO}$ content and lower aluminium oxide $\left(\mathrm{Al}_{2} \mathrm{O}_{3}\right)$ content of slag are responsible for the longer setting times and delayed strength development compared to CEMI-only samples. In the present study, it was observed that the $\mathrm{Al}_{2} \mathrm{O}_{3}$ content in the matrix was not significantly affected by the replacement of $\mathrm{PC}$ by slag as steel slag contains as much $\mathrm{Al}_{2} \mathrm{O}_{3}$ as PC. Therefore, minimal delays in setting times and weakened strength development were observed. Compared to steel slag, $\mathrm{PC}$ contains more $\mathrm{C}_{3} \mathrm{~S}$, which is mainly responsible for the hydration reactions and hence for strength development. However, the reactivity of steel slag is a factor that determines its strength development efficiency. The basicity of steel slag is interrelated to its reactivity, which only increases with its basicitiy. The basicity of steel slag also increases the free $\mathrm{CaO}$ content, which may cause volume expansion problems in real world applications and is not considered to be convenient [4]; [9]. All slag-blended mixtures achieved UCS values higher than $1 \mathrm{MPa}$ for most of the mix ratios studied, regardless of the curing age. The strength development continued at later ages, i.e., 56 days, regardless of the mixture. This finding is consistent with a previous study focused on PFA- blended specimens [10]. In another published study that focused on the use of a ground-granulated blast-furnace slag (GGBS), the strength gain increased in time as the GGBS content was increased. The formation of calcium hydroxides requires time and the pozzolanic reactions are slow. Hence, the strength development continues over time. The results of the present study are consistent with those obtained in the literature [6]. Moreover, it is important to note that the UCS values achieved with the addition of GGBS ranged from 9.7 to $48.4 \mathrm{MPa}$ at 28 days, whereas the UCS values achieved with the addition of steel slag in this study were in the range of 22.9 to $37.5 \mathrm{MPa}$. The amount of steel slag incorporated (CEMI-slag 1:4) into the mix matrix studied was much higher than that published by [6], i.e., CEMI-slag 280:440 and on average, better strength development was achieved 
compared to GGBS-blended mixes. According to the same researchers, the optimum amount of GGBS addition was about $55-59 \%$ of the total binding used in the mixture. Overall, steel slag performance was much better than GGBS-blended mixtures in terms of consistency, UCS and setting times and the optimum ratio of slag incorporation was $80 \%$ (CEMI-slag 1:4). UCS measurements are mainly used to assess the progress of the hydration reactions as, if the hydration reactions progress successfully, then the strength at each successive age $(7,28$, and 56 days $)$ is greater than the previous age.

Even though the strength development of slagblended mixtures is not as good as cement blends, the UCS values achieved with slag blends are very high due to the high $\mathrm{SiO}_{2}$ content of steel slag, which initiates the calcium silicate hydrates formation required for strength development. Amongst all mix ratios studied, slag achieved the best strength development at 56 days for most of the ratios, showing that the hydration reactions still continue until that time. However, for most of the ratios studied, slag achieved the highest UCS values just after the CEMI-only blended samples.

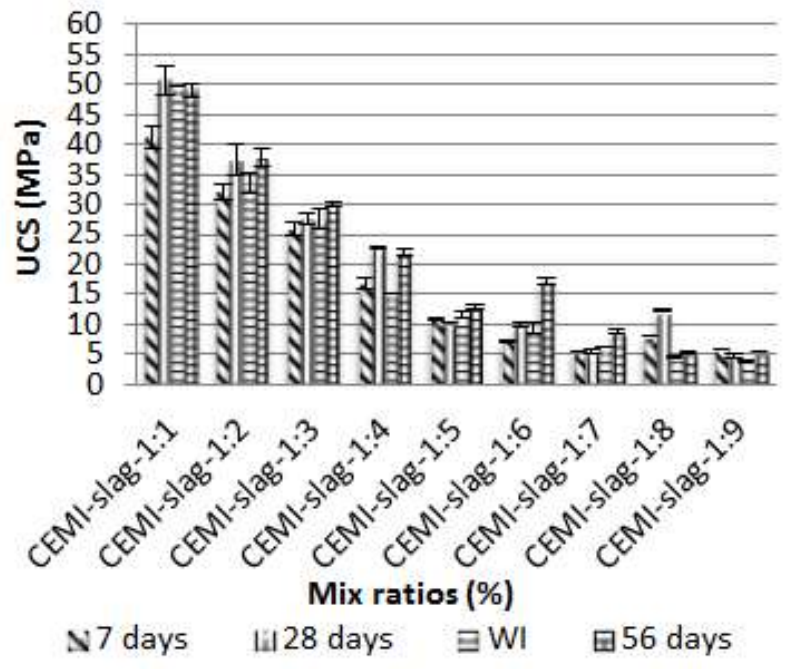

Fig. 3. CEMI-slag mix combinations for UCS 7, 28, and 56 days, WI (28 days) ( ${ }^{*}$ Error bars with standard deviations included)

\subsubsection{Mineralogical and Micro-Structural Analyses: $X$-Ray Diffraction (XRD) Analysis Results CEMI- slag 1:2 at 28 days}

The mineralogical composition of different steel slags has been investigated by various researchers [12-16]. When XRD analysis of steel slag was undertaken, a complex structure was observed due to the overlapping peaks, which indicates that crystalline phases exist in steel slag. [15] reported that steel slag is mainly composed of wustite - $\mathrm{FeO}$; calcium ferrite $\mathrm{CaFe}_{2} \mathrm{O}_{4} /(\mathrm{CF})$; srebrodolskite - $\mathrm{Ca}_{2} \mathrm{Fe}_{2} \mathrm{O}_{5} /\left(\mathrm{C}_{2} \mathrm{~F}\right)$; larnite $\mathrm{Ca}_{2} \mathrm{SiO}_{4} /\left(\mathrm{C}_{2} \mathrm{~S}\right)$; alite - $\mathrm{Ca}_{3} \mathrm{SiO}_{5}\left(\mathrm{C}_{3} \mathrm{~S}\right)$; mayenite $\left.\mathrm{Ca}_{12} \mathrm{Al}_{14} \mathrm{O}_{33} / \mathrm{C}_{12} \mathrm{~A}_{7}\right)$; brownmillerite $\left.\mathrm{Ca}_{2}(\mathrm{Al}, \mathrm{Fe})_{2} \mathrm{O}_{5}\right) /\left(\mathrm{C}_{4} \mathrm{AF}\right)$; calcium ferrite $-\mathrm{CaFe}_{2} \mathrm{O}_{4} /(\mathrm{CF})$ and rankinite $-\mathrm{Ca}_{3} \mathrm{Si}_{2} \mathrm{O}_{7}\left(\mathrm{C}_{3} \mathrm{~S}_{2}\right)$. Another study by
Nicolae et al. (2007) showed that the main mineralogical components are larnite, alite, mayenite, brownmillerite, gehlenite, wustite, magnetite, quartz and periclase. The major components, namely, brownmillerite, alite, mayenite, wustite and larnite, are similar in both studies with the differences in composition mainly due to the origin of the steel slag.

The results show that the periclase, gehlenite and calcite are similar to those found in the published literature. $\mathrm{C}_{4} \mathrm{AF}$, which is one of the major mineral phases of PC, was detected in the steel slag. This shows that the ferrite phase was generated since the trivalent iron was able to combine with calcium alumina [11]. It is important to note that not all the peaks in the pattern could be modelled in the Rietveld refinement. Hence, no quantitative Rietveld analysis can be provided. Magnesium aluminium iron oxide and calcium aluminium oxide fluoride could not be identified, mainly due to Fe fluorescence background noise and hence poor data.

Steel slag has a chemical composition similar to PC. The high Fe content of steel slag that usually exists in both the di- and tri-trivalent states is the only main difference between PC and steel slag. XRD confirmed the absence of $\gamma-C_{2} S$. The mineralogical phases detected in the samples are calcite as the principal component, along with periclase, portlandite, quartz, vaterite, aragonite, annite mica and $\beta-\mathrm{C}_{2} \mathrm{~S}$. X-ray reflection peaks were observed at $26.6^{\circ}$ for quartz, $18^{\circ}, 34^{\circ}$ and $47.5^{\circ}$ for portlandite, $29.5^{\circ}$ for calcite and $43^{\circ}$ and $62.2^{\circ}$ for periclase at $2 \theta$. The highest peak was achieved at $43^{\circ}$ with periclase. These results are in agreement with the Retvield analysis and confirm periclase as one of the major phases observed in this sample. The cement hydration product, portlandite, existed in the XRD analysis of this sample, which confirms that hydration reactions had taken place. The periclase, calcite and quartz phases detected in this sample were also found in the as-received steel slag. However, vaterite, aragonite, $\beta-\mathrm{C}_{2} \mathrm{~S}$ and annite mica phases were only detected in this sample after being mixed with cement and cured for 28 days.

Table 2. Quantitative Analysis - Rietveld.

\begin{tabular}{|l|c|}
\hline Phase 1: Periclase & $20.25 \%$ \\
\hline Phase 2: Calcite & $22.63 \%$ \\
\hline Phase 3: Portlandite & $6.02 \%$ \\
\hline Phase 4: Quartz & $4.41 \%$ \\
\hline Phase 5: Vaterite & $17.33 \%$ \\
\hline Phase 6: Aragonite & $15.45 \%$ \\
\hline Phase 7: "C $\mathrm{C}_{2}$ S beta (MUMME)" & $11.27 \%$ \\
\hline Phase 8: "Annite mica" & $2.64 \%$ \\
\hline
\end{tabular}

\subsubsection{CEMI-slag 1:4 at 28 days}

The mineralogical phases detected in the samples were calcite as the principal component, along with periclase, portlandite, ettringite, gypsum, larnite, brucite, quartz, vaterite, aragonite, and $\beta-\mathrm{C}_{2} \mathrm{~S}$. XRD confirmed the absence of $\gamma-\mathrm{C}_{2} \mathrm{~S}$. X-ray reflection peaks were observed at $11.8^{\circ}, 20.8^{\circ}$ and $29^{\circ}$ for gypsum, $18^{\circ}, 28.6^{\circ}, 34.1^{\circ}$, 
$47^{\circ}$ and $50.8^{\circ}$ for portlandite, $23^{\circ}, 29.4^{\circ}, 36^{\circ}, 43^{\circ}, 47.4^{\circ}$ and $57.5^{\circ}$ for calcite and $43^{\circ}$ and $62.1^{\circ}$ for periclase at $2 \theta$. The highest peak was achieved at $43^{\circ}$ with periclase. These results are in agreement with the Retvield analysis and confirm periclase as the major phase observed in this sample (see Table 3). The ettringite phase, which is one of the first hydration products during hydration of cements, was observed in the XRD of this sample. Portlandite was also present, which confirms that hydration reactions took place. The periclase, calcite, brucite and quartz phases detected in this sample were also found in the as-received steel slag. Gypsum was also detected in the as-received cement and EAFD. However, the vaterite, aragonite, $\beta-\mathrm{C}_{2} \mathrm{~S}$ and ettringite phases were only detected in this sample after being mixed with cement and cured for 28 days. As previously reported, both CEMI-slag 1:2 and 1:4 mix combinations without waste addition demonstrated very good strength development when compared to cement-only pastes after 28 days of curing. The phases observed in the XRD analyses of these samples confirmed the strength development results reported in the previous chapters. The formation of hydration products and hence their existence in the XRD analysis at high ratios showed that the cement hydration continued and the hydration products required for strength development were formed.

Table 3. Quantitative Analysis - Rietveld.

\begin{tabular}{|l|r|}
\hline Phase 1: Periclase & $11.59 \%$ \\
\hline Phase 2: Calcite & $22.28 \%$ \\
\hline Phase 3: Portlandite & $8.29 \%$ \\
\hline Phase 4: Quartz & $2.86 \%$ \\
\hline Phase 5: Vaterite & $5.03 \%$ \\
\hline Phase 6: Aragonite & $7.79 \%$ \\
\hline Phase 7: "C 2 S beta (MUMME)" & $16.23 \%$ \\
\hline Phase 8: Ettringite & $6.75 \%$ \\
\hline Phase 9: Gypsum & $18.98 \%$ \\
\hline
\end{tabular}

\subsubsection{SEM Analysis of Slag and its blends}

The elemental analysis showed that steel slag was composed of $\mathrm{O}, \mathrm{Mg}, \mathrm{Al}, \mathrm{Si}, \mathrm{S}, \mathrm{K}, \mathrm{Ca}, \mathrm{Ti}, \mathrm{Mn}, \mathrm{Fe}, \mathrm{Zn}$ and $\mathrm{Pb} . \mathrm{O}, \mathrm{Ca}, \mathrm{Fe}$ and $\mathrm{Mg}$ were the main elements with very low levels of Ti, S, K, $\mathrm{Zn}$ and $\mathrm{Pb}$. The high amount of $\mathrm{O}$ indicates that elements were mostly in the oxide forms with magnesium, iron and calcium oxide being the main ones. This could be an indication of the presence of wustite $(\mathrm{FeO})$, which is expected in steel slag but could not be detected by XRD analysis. The presence of calcite was verified by SEM-EDX analysis. The presence of $\mathrm{Mg}, \mathrm{Si}$ and $\mathrm{Al}$ in steel slag verifies the existence of other phases including calcite, brucite, periclase and wollastonite.

\subsubsection{CEMI-slag 1:2:0 at 28 days}

The SEM image of CEMI-SLAG 1:2 with no waste addition after 28 days' curing is shown in Figure 5. The quantitative analysis from EDX showed that this sample is composed of $\mathrm{C}, \mathrm{O}, \mathrm{Mg}, \mathrm{Al}, \mathrm{Si}, \mathrm{Cl}, \mathrm{Fe}$ and $\mathrm{Ca}$, with $\mathrm{C}$,
$\mathrm{O}, \mathrm{Mg}$ and $\mathrm{Ca}$ as the main elements. EDX reveals the presence of $\mathrm{O}, \mathrm{Mg}, \mathrm{C}$ and $\mathrm{Ca}$, which are mainly attributed to calcite, portlandite, vaterite and aragonite. Other particles contain mainly $\mathrm{Si}, \mathrm{Fe}$ and $\mathrm{Mg}$. This is attributed to periclase, quartz, larnite and annite, as also confirmed by XRD analysis.

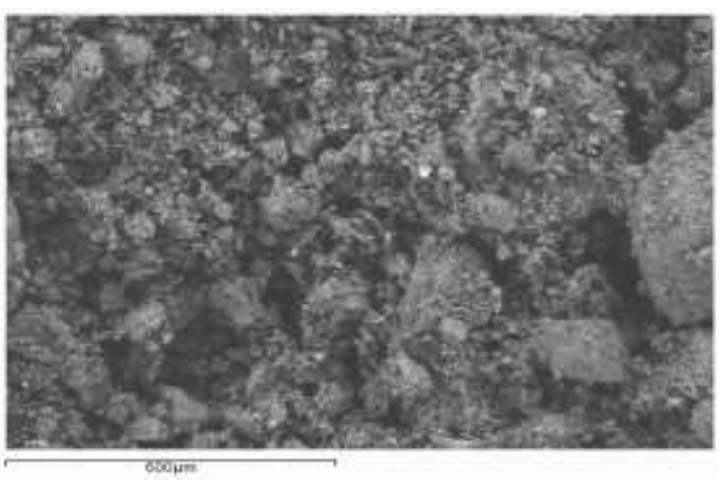

Fig. 4. SEM image of steel slag as received.

Table 4. Quantification of steel slag.

\begin{tabular}{|c|c|c|}
\hline Element & Weight \% & Atomic \% \\
\hline $\mathrm{O}$ & 50.19 & 69.66 \\
\hline $\mathrm{Mg}$ & 6.68 & 6.10 \\
\hline $\mathrm{Al}$ & 4.68 & 3.85 \\
\hline $\mathrm{Si}$ & 4.77 & 3.77 \\
\hline $\mathrm{S}$ & 0.66 & 0.46 \\
\hline $\mathrm{K}$ & 0.40 & 0.23 \\
\hline $\mathrm{Ca}$ & 19.95 & 11.05 \\
\hline $\mathrm{Ti}$ & 0.31 & 0.14 \\
\hline $\mathrm{Mn}$ & 2.00 & 0.81 \\
\hline $\mathrm{Fe}$ & 9.36 & 3.72 \\
\hline $\mathrm{Zn}$ & 0.41 & 0.14 \\
\hline $\mathrm{Pb}$ & 0.59 & 0.06 \\
\hline $\mathrm{Total}$ & 100.00 & \\
\hline
\end{tabular}

Crystalline structures in this sample (shown by arrows) are likely the products of hydration reactions. Mapping results of the magnified area (not provided here) show that $\mathrm{Ca}$ and $\mathrm{Si}$ are the dominant elements, which could be an indication of hydration products (C-H and C-S-H gel). The strong strength development obtained supports this statement, as the slag-blended mix combinations exhibited high strength development compared to other mix blends. 

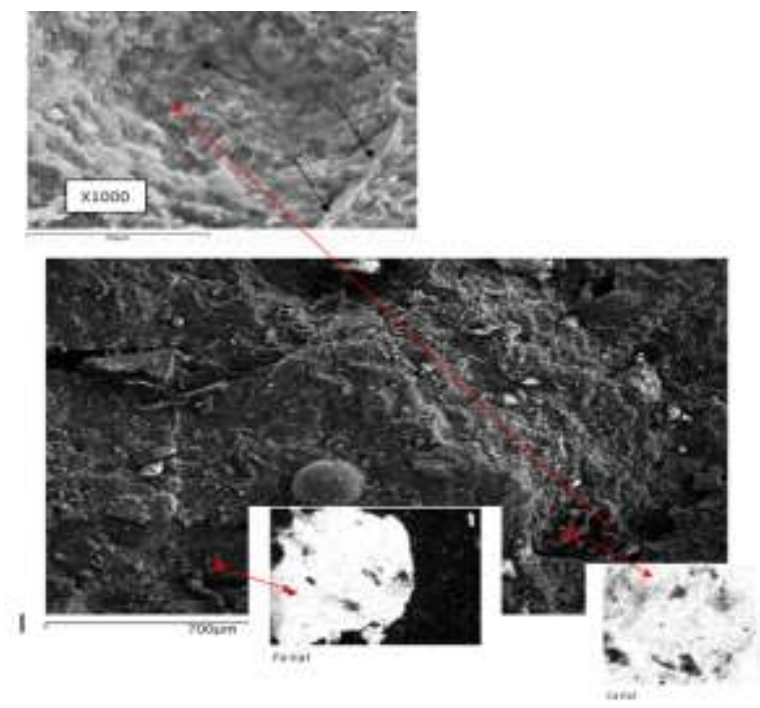

Fig. 5. SEM image of CEMI-slag 1:2:0 at 28 days - large area scan (X90).

\section{Conclusions}

The results show that almost all blended mix ratios studied were successful in terms of physical integrity including UCS, setting time and consistency tests.

The best physical performances were achieved in the following order: CEMI-only > CEMI-slag.

However, most of the slag-blended samples achieved higher UCS values than CEMI-only samples at longer curing ages ( $\geq 28$ days).

The high $\mathrm{MgO}$ and $\mathrm{Fe}$ content of steel slag resulted in the formation of magnetite and magnesioferrite.

SEM analysis was able to detect the formation of cement hydration products (portlandite and ettringite).

Effective replacement of cement by steel slag at a ratio of 1:4 significantly improves both the economic and sustainability characteristics of cement replacement.

\section{References}

[1] J.Lee, J. Choi, T. Yuan, Y. Yoon, D. Mitchell, Comparing Properties of Concrete Containing Electric Arc Furnace Slag and Granulated Blast Furnace Slag, MDPI- Materials, 12, 1371 (2019).

[2] I.Z. Yildirim, M. Prezzi, Chemical, mineralogical and morphological properties of steel slag, Advances in Civil Engineering, 1-13 (2011).

[3] R.D. Young, Method and apparatus for using steel slag in cement clinker production, U.S. Patent no. 5421880, Dallas, TX (1995).

[4] C. Shi, J. Qian, High performance cementing materials from industrial slags - a review, Resources, Conservation and Recycling, 29, 195207 (2000).

[5] C. Shi, R. D. Spence, General Guidelines for S/S of wastes, in Spence, R. D. and Shi, C. (eds.),Stabilization and Solidification of Hazardous, Radioactive and Mixed Wastes, CRC Press, 7-24 (2005).
[6] A. Oner, S. Akyuz, An experimental study on optimum usage of $\mathrm{GG} \mathrm{S}$ for the compressive strength of concrete, Cement and Concrete Composites, 29, 505-514 (2007).

[7] C. Shi, Steel slag - Its production, processing, characteristics and cementitious properties, Journal of Materials in Civil Engineering, 16, 230-236 (2004).

[8] I.A. Altun,I. Yilmaz, Study on steel furnace slags with high $\mathrm{MgO}$ as additives in Portland cement, Cement and Concrete Research, 32, 13 (2002).

[9] C.Shi, R.L. Day, Early strength development and hydration of alkali-activated blast furnace slag/fly ash blends, Advances in Cement Research, 11, 189196 (1999).

[10] S.Asavapisit, S.Naksrichum, N.Harnawarjanawong, Strength, leachability and microstructure characteristics of cement-based solidified plating sludge, Cement and Concrete Research, 35, 10421049 (2005).

[11] S. Turkel, Long-term compressive strength and some other properties of controlled low strength materials made with pozzolanic cement and class $\mathrm{C}$ fly ash, Journal of Hazardous Materials, 137, 261266(2006).

[12] M.Tossavainen, F.Engstrom, Q. Yang,N.Menad, M.L. Larsson, B. Bjorkman, Characteristics of steel slag under different cooling conditions, Waste Management, 27, 10, 1335-1344 (2007).

[13] P.E. Tsakiridis, G.D. Papadimitriou, S.Tsivilis, C. Koroneos, Utilization of steel slag for Portland cement clinker production, Journal of Hazardous Materials, 152, 805-811(2008).

[14] L.J.Vandeperre, M.Liska, A. Al-Tabba, Microstructure of reactive magnesia cement blends, Cement and Concrete Research, 30, 706-714 (2008).

[15] T.Sofilic, A.Mladennovic, U. Sofilic, Characterization of the EAF steel slag as aggregate for use in road construction,Proceedings of the 4th International Conference on Safety and Environment in Process Industry, Florence: Italy,Italian Association of Chemical Engineering (2010).

[16] H.F.W. Taylor, Reactions and reactivities of compounds in hydraulic cements, Solid State Ionics, 43, 31-35 (1990). 